\title{
POLÍTICA ENERGÉTICA NA AMAZÔNIA: A UHE ESTREITO E OS CAMPONESES TRADICIONAIS DE PALMATUBA/ BABAÇULÂNDIA (TO)
}

\section{Energy statecraft in Amazonian: the UHE Estreito and the traditional peasants Palmatuba/Babaçulândia (TO)}

\author{
Airton Sieben \\ Professor no Depto. de Geografia, Universidade Federal do Tocantins \\ asieben@uft.edu.br \\ João Cleps Junior \\ Prof. Dr. Instituto de Geografia, UFU. Bolsista CNPq. \\ jcleps@ufu.br
}

Artigo recebido em 04/03/2012 e aceito para publicação em 24/03/2012

RESUMO: A política energética brasileira está pautada na construção de hidrelétricas. As usinas hidrelétricas causam transtornos às populações atingidas e alagam grandes áreas de terras férteis. Neste trabalho buscou-se analisar a política energética brasileira frente ao crescimento econômico nacional e como a construção de barragens influenciou o modo de vida de comunidades atingidas na Amazônia, sobretudo no processo de reivindicação das indenizações. Quanto à metodologia, pesquisou-se sobre a política energética em sites e literaturas, analisando com roteiro de entrevista e acompanhou-se a luta de camponeses atingidos para terem reconhecidos os seus direitos. Este estudo é sobre a comunidade ribeirinha do rio Tocantins de Palmatuba, em Babaçulândia/TO, atingida pelo reservatório da UHE de Estreito. O estado do Tocantins tem na política energética da sucessão de lagos artificiais, no rio homônimo, um dos modelos para crescer economicamente. Esta política desterritorializou camponeses tradicionais com a justificativa do desenvolvimento sustentável. Investimentos em alternativas energéticas deveriam ser feitos, pois o Brasil dispõe de várias fontes de energia menos onerosas.

Palavras chaves: território, monocultura das águas, camponês tradicional.

RESUMEN: La política energética brasileña está basada en la construcción de hidroeléctricas. Las plantas hidroeléctricas causan trastornos a las poblaciones afectadas e inundan grandes áreas de tierras fértiles. En este trabajo se buscó analizar la política energética brasileña frente al crecimiento económico nacional y como la construcción de presas influenció el modo de vida de comunidades afectadas en el Amazonas, sobre todo en el proceso de reclamación de las indemnizaciones. En cuanto a la metodología, se investigó sobre la política energética en sitios y literaturas, analizando con guión de entrevista y se acompañó la lucha de campesinos afectados para tener sus derechos reconocidos. Este estudio es sobre la comunidad ribereña del rio Tocantins de Palmatuba, en Babaçulândia/TO, afectada por el depósito de la UHE de Estreito. El estado de Tocantins tiene una política energética de sucesión de lagos artificiales en el río homónimo, uno de los modelos para crecer económicamente. Esta política desalojó campesinos tradicionales son la justificación del desarrollo sostenible. Inversiones en alternativas energéticas deberían ser hechas, ya que Brasil dispone de varias fuentes de energía menos costosas.

Palabras clave: territorio, monocultivo del agua, campesino tradicional. 


\section{INTRODUÇÃO}

A necessidade crescente de energia no país ocasionou inúmeros problemas ao ambiente e aos atingidos pelos reservatórios das hidrelétricas, principal matriz na política energética do Brasil. A vislumbração da elite política e econômica do país em se tornar a $5^{\circ}$ economia mundial é o principal agente na intensificação em se ampliar o potencial energético. Tal iniciativa, por certo impõe maiores impactos ao país como um todo, sobretudo em comunidades que vivem próximas às margens de rios e neles mantêm relação orgânica extraindo dos canais fluviais seu sustento.

Neste trabalho buscou-se discutir a relação do Estado com o capital e a forma deste articular a política energética a fim de proporcionar os planos de crescimento econômico do país. As leis e políticas energéticas foram observadas para analisar a legitimidade dos empreendimentos hidrelétricos, sobretudo na Amazônia. Discutiu-se a função da região norte na monocultura da água, e a maneira do estado do Tocantins se organizar a fim de receber os empreendimentos hidrelétricos. Observou-se a Usina Hidrelétrica de Estreito e de como esta estrutura atingiu as comunidades de camponeses tradicionais de Palmatuba em Babaçulândia.

A fim de elaborar esta discussão foram feitas leituras sobre autores que discutem o Estado, o estado na Amazônia e consultas em sites da internet para discutir sobre a política energética brasileira. Foram feitas saídas de campo no período de 2009 e de 2010 aplicando entrevistas aos atingidos da comunidade de Palmatuba.

Observou-se manifestações dos atingidos e participou-se de reuniões entre os camponeses tradicionais de Palmatuba e os representantes do empreendedor, Consórcio Estreito de Energia (CESTE). Foram feitos registros fotográficos e elaborou-se mapas a fim de dar subsídios a discussão.

$\mathrm{O}$ estado do Tocantins está localizado na Grande Região Norte do país, pertencente à Amazônia Legal (Figura 01). À jusante de Babaçulândia estão localizados os municípios de Aguiarnópolis (TO) e Estreito (MA). Aguiarnópolis e Estreito se localizam ao norte do Tocantins e sudoeste do Maranhão, respectivamente.

Figura 01: Localização da área de estudo

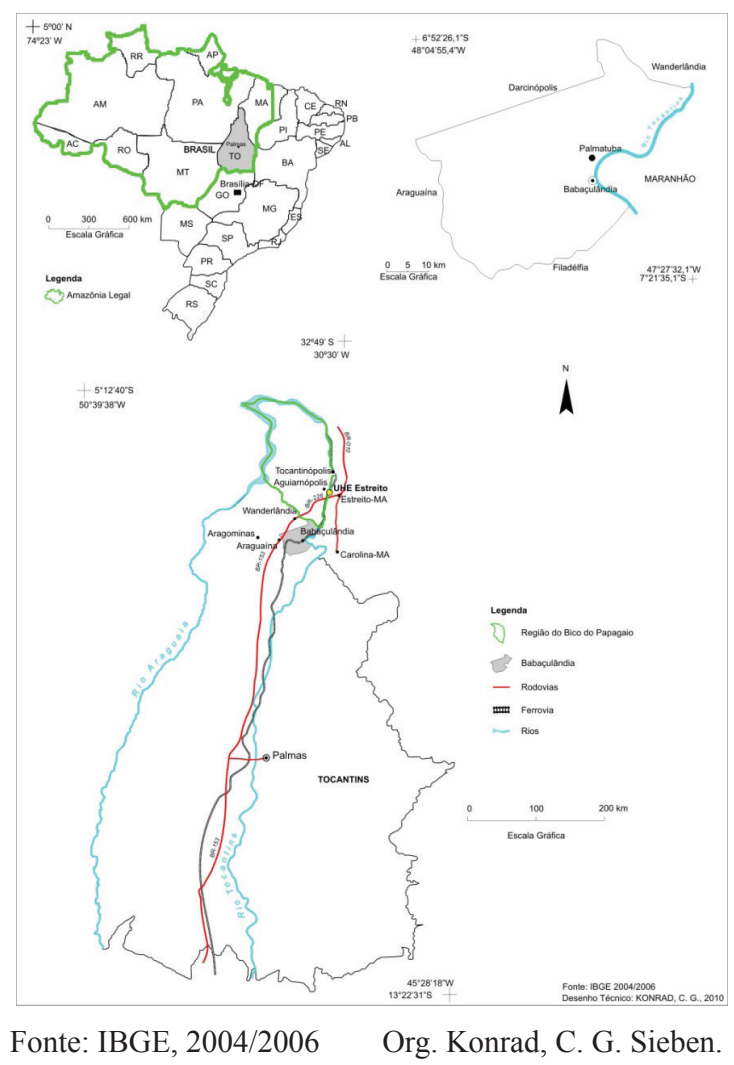

Soc. \& Nat., Uberlândia, ano 24 n. 2, 183-196, mai/ago. 2012 
A UHE Estreito recebeu este nome por estar localizada no município homônimo. É neste município que ficaram as maiores obras inclusive com a casa de máquinas. Estreito é distante aproximadamente $100 \mathrm{~km}$ da cidade de Babaçulândia (Mapa 1). O local foi escolhido pelas feições geológicas e pelo estreitamento do canal do rio Tocantins. Além disto, é o encontro das rodovias federais 226 (trecho Belém-Brasília), com a BR - 230 e a BR - 010 (trecho Transamazônica) e da ferrovia Norte-Sul. Isto possibilitará o futuro transporte multimodal entre rodovia, ferrovia e hidrovia.

O lago atinge as cidades e áreas rurais dos municípios de Babaçulândia e Filadélfia e área rural dos municípios de Darcinópolis e Wanderlândia (TO). Pelo lado maranhense atinge a cidade e área rural do município de Carolina e em Estreito a barragem foi construída a montante da cidade, atingindo áreas rurais do município. Ressalta-se que estes são os impactos diretos. Ao todo 12 municípios foram atingidos pelo lago, sendo 10 tocantinenses.

A UHE Estreito foi implementada no decorrer da $1^{\circ}$ dezena do novo milênio. O lago artificial foi formado no $1^{\circ}$ trimestre do ano de 2011. Nos anos de 2004/05 aconteceram as audiências públicas, gerando muitas dúvidas nos atingidos. Os camponeses tradicionais de Palmatuba foram desterritorializados no início do ano de 2009, quando ocorreu a indenização.

\section{ABORDAGENS SOBRE A POLÍTICA ENERGÉ- TICA BRASILEIRA}

Os grandes projetos hidrelétricos no Brasil remontam do início da década de 1960 no governo de "esquerda" de João Goulart que em comum acordo com o governo de Alfredo Stroessner do Paraguai deram início ao projeto da construção da Itaipu Binacional. A maior hidrelétrica mundial foi concluída no ano de 1982 (GERMANI, 2003).

A intensificação da produção de energia elétrica no país se deu entre os anos 1975 e 1985, aumentando a capacidade de geração de $18.500 \mathrm{Mw}$ para $54.000 \mathrm{Mw}$. A crise da década de 1980, as críticas às barragens e atuação de organismos internacionais financiadores no sentido de estabelecer orientações dificultaram a construção de barragens. Mesmo assim o governo brasileiro pretende construir 432 novas barragens até o ano 2015 (ZITZKE, 2007). Com o aumento do fornecimento energético atual o Brasil visa chegar a aproximadamente 120 mil Mw em 2020.

O setor elétrico teve domínio sobre os recursos hídricos pelo amparo legal do decreto $n^{\circ} 24.643 / 34$ no Código das Águas. A justificativa foi que havia uma legislação obsoleta em desacordo com as necessidades da coletividade, precisava-se fazer de uso racional das águas e permitir ao poder público o controle e incentivo industrial da água, promovendo o crescimento econômico baseado na hidreletricidade (BRASIL, Decreto $n^{\circ} 24.643 / 34$ ).

Nos anos de 1980 foi criado o Conselho Nacional de Meio-Ambiente (CONAMA) e definiu-se a Política Nacional de Meio Ambiente. Exigiam-se os Estudos de Impacto Ambiental e Relatório de Impacto Ambiental (EIA-Rima), a fim de minimizar os efeitos negativos do empreendimento. Estes dois documentos serviram como instrumento à Avaliação de Impacto Ambiental (AIA), segundo Brasil (Lei 6938/81).

Nos anos de 1990, houve a abertura econômica brasileira dos governos neoliberais para a privatização, reorientando o setor da energia para a iniciativa privada. Criou-se uma série de órgãos e situações a fim de pressionar o empreendedor a cumprir suas responsabilidades ambientais e sociais, sobretudo neste último. O objetivo era minimizar os impactos negativos sobre os atingidos com o auxílio de ONG's, instituições científicas, procuradorias etc., dando transparência aos projetos hidrelétricos (ZITZKE, 2007).

A Lei das Concessões dispõe sobre o regime e permissão da prestação de serviços públicos. Esta lei viabiliza maior participação de capitais privados, diminuindo a atuação do poder público e induzindo a competição na construção de novos projetos pela regulamentação do regime de licitação das concessões. As concessões eram, antes desta lei, outorgadas apenas às concessionárias estaduais ou federais (BRASIL, Lei $\left.\mathrm{n}^{\circ} 8.987 / 95\right)$.

Em função da crise de energia, o CONAMA instituiu um grupo de trabalho para reavaliar a Resolução $n^{\circ} 06 / 87$ visando a simplificar e a agilizar os procedimentos de licenciamento de empreendimentos do Setor de Energia Elétrica. Ressalta-se que a resolução citada estabelece os critérios para o licenciamento do empreendimento do setor de energia elétrica, bem 
como as etapas do empreendimento nas quais as licenças devem ser solicitadas. Esta resolução coloca que caso o empreendimento necessite ser licenciado por dois estados, estes deverão entrar em entendimento prévio a fim de uniformizar as exigências (BRASIL, Resolução $n^{\circ}$ 06/87).

Pela UHEE estar situada em dois territórios estaduais as licenças passaram por aprovação do Instituto Brasileiro do Meio Ambiente (IBAMA) e pelos institutos estaduais, o Sistema Estadual do Meio Ambiente (SISEMA) no Maranhão e Instituto de Natureza do Tocantins (NATURATINS). Apesar de o estado do Tocantins ter o maior número de municípios atingidos a casa de máquinas se situa no estado do Maranhão. Suspeita-se que o poder político e econômico do estado nordestino tenha prevalecido por esta opção.

A Agência Nacional das Águas (ANA) é a entidade ou órgão federal responsável pela implementação da Política Nacional de Recursos Hídricos e pela Coordenação do Sistema Nacional de Gerenciamento de Recursos Hídricos. A ANA é quem autoriza o uso dos recursos hídricos nos corpos d'água de domínio da União, através do regime de licitação. As licitações são abertas a empresas ou instituições fornecendo uma concessão para a construção e operação de usinas hidrelétricas (BRASIL, Lei n ${ }^{\circ}$ 9.984/2000).

A concessão deve ser licitada pela Agência Nacional de Energia Elétrica (ANEEL). Esta viabiliza junto a ANA, a obtenção prévia de declaração de reserva de disponibilidade hídrica. A Administração Pública, quando necessário, pode impor a elaboração de EIA-Rima (CNEC, 2001). Conforme o relatório de $\operatorname{CNEC}(2001,20)$ : "O licenciamento ambiental é um procedimento administrativo, instrumento da Política Nacional do Meio Ambiente, através do qual a Administração pública controla e fiscaliza as ações dos administrados...”

No início do milênio, ocorreram as crises de abastecimento elétrico, gerando a falta de energia em várias cidades do país. A fim de evitar a interrupção imprevista do suprimento de energia elétrica foi criada a medida provisória do Apagão, criando desta forma a Câmara de Gestão da Crise de Energia Elétrica (GCE). A medida visava ao enfrentamento da crise energética no país, (BRASIL, Medida Provisória ${ }^{\circ}$ 2.198-5/2001).
... duas mudanças são marcantes: a substituição do sistema estruturado por empresas de capital estatal por um sistema formado por capitais privados $e$ a reforma do setor elétrico, que visa assegurar à sociedade energia a preços competitivos, com qualidade e quantidade. Vale ressaltar que estas mudanças iniciam quase que ao mesmo tempo em que a Lei dos Recursos Hidricos é aprovada, em 1996, e que o sistema elétrico brasileiro é constituído fundamentalmente por hidrelétricas. Neste contexto, foi aprovado o plano Nacional de Energia Elétrica 1993/2015 - Plano 2015 que previu a participação de investidores privados nos empreendimentos de geração, transmissão e distribuição de energia elétrica. (ZITZKE, 2007, p. 68).

A área de energia no Brasil sempre esteve excluída em governos anteriores. A matriz energética brasileira está privilegiando a introdução de gás natural, mais caro e raro com o uso de tecnologia e equipamentos importados. A demanda de energia no Brasil é crescente, haja vista a inserção de mais brasileiros em condições socioeconômicas melhores. $\mathrm{O}$ consumo per capta de energia no Brasil era um dos menores do mundo e o Programa Luz para Todos tem como critério de priorização fornecer energia elétrica para comunidades mais carentes como atingidos por barragens, quilombolas, aldeia indígenas entre outros (ROUSSEFF, 2007).

No contra ponto da discussão sobre hidrelétricas, Sigaud comenta a experiência da UHE de Sobradinho, como exemplo altamente negativo sobre os efeitos às populações atingidas. "Em Sobradinho, a retomada do processo produtivo exigiu dos camponeses uma mudança significativa de suas práticas habituais e os constrangeu a uma modernização compulsória, a qual se realizou em condições bastante desfavoráveis" (SIGAUD, 1992, p. 7).

...se crescermos a taxas de 4,5\%, se houver distribuição de renda adequada - aquela que queremos quando parcelas importantes da população são incorporadas a niveis cada vez maiores de renda - iremos precisar de uma quantidade de energia bastante significativa.

Soc. \& Nat., Uberlândia, ano 24 n. 2, 183-196, mai/ago. 2012 
Esta quantidade de energia, bastante significativa, não pode ser produzida a qualquer preço. Não temos como fornecer energia a preços proibitivos para os níveis de renda nacional. Outra forma de exclusão é através de preços mais elevados. (ROUSSEFF, 2007, p. 78).

Cappio (2007) argumentou que não se pode destruir matas, acabar com a piracema, afogar terras férteis e remover pessoas somente em nome do progresso. Cappio (2007, p. 91) manifestou: "Nosso povo já sofreu muito com a construção de barragens. Precisamos buscar outras fontes de energia, menos prejudiciais ao ser humano e a todas as formas de vida. Dizer que não temos outras saídas é renunciar ao uso da inteligência e da criatividade." Alternativas existem.

O Brasil detinha o mais limpo sistema hidrelétrico do mundo. Cometendo barbaridades, expulsando o povo das suas terras com essas barragens estúpidas, desnecessárias, o governo FHC - esse traidor! - entregou a grupos externos essa riqueza. Bandido! Bandido! Não tem direito de jogar com a vida de um povo; usar o poder para satisfazer sua ambição desmedida, sua falta de caráter e sua falta de compostura. Entretanto, o atual governo não está revertendo estas coisas. (VIDAL, 2007, p. 100).

No Fórum Nacional Terra e Água o físico, engenheiro e professor da Universidade de Brasília (UnB), Bautista Vidal foi enfático ao se apresentar contra o atual modelo de política energética no Brasil. Questionando atitudes do governo em beneficiar empresas de capital internacional.

Eu queria a ministra (de Minas e Energia, Dilma Rousseff) estivesse aqui. Por quê? Por quê? Porque entregou $80 \%$ da distribuição de energia elétrica a empresas estadunidenses falidas, que usam o dinheiro do trabalhador para comprar e não pagam! Caloteiros! Ladrões! Por que o Governo Lula não bota esta gente na cadeia? Por quê? (VIDAL, 2007, p. 101).

No Brasil decisões importantes que atingem toda a sociedade, infelizmente são tomadas a fim de favorecer uma pequena parcela da sociedade e de interesses internacionais. Esta atitude interesseira e lucrativa para poucos prejudica a maior parte da população que paga pela política econômica exploratória do Brasil.

\section{ALTERNATIVAS ELÉTRICAS}

Inúmeras são as fontes de energia. Cada uma tem seus aspectos negativos e positivos. Os fatores que decidem a preferência por uma em detrimento da outra são as decisões políticas e econômicas. Zitzke (2007) comentou que as constantes alterações e anúncios de normas e medidas provisórias no setor elétrico inibem os investidores que pretendem investir em fontes alternativas.

A energia solar, por exemplo, poderia ser amplamente utilizada, mas por questões de custos e concorrências de outras fontes impõe um limite ao seu uso. As florestas são outra fonte que transforma a energia solar em calorífica e, portanto, poderiam existir projetos de florestamento em área degradas.

A Resolução 233/99 da ANEEL estabeleceu os valores normativos de algumas fontes alternativas de energia. Na tabela 1 as hidrelétricas e termelétricas a gás natural e termelétrica a carvão nacional apresentam os valores mais baixos com 57,2 e $61,8 \mathrm{R} \$$ Mwh, respectivamente. As Pequenas Centrais Hidrelétricas (PCH's) e termelétrica de biomassa apresentam valores intermediários, respectivamente com 71,3 e 80,8 R $\$$ /Mwh. A usina eólica e usina solar foto-voltaica apresentam, correspondentemente os valores mais elevados com 100,9 e 237,5 R $\$$ Mwh. 
Política energética na Amazônia: a UHE Estreito e os camponeses tradicionais de Palmatuba/Babaçulândia (TO)

Airton Sieben, João Cleps Junior

Tabela 1 - Valores normativos de energia elétrica

\begin{tabular}{l|l}
\hline Fonte & Valor normativo R\$/ \\
\hline Hidrelétrica e termelétrica a gás & 57,2 \\
\hline Termelétrica a carvão nacional & 61,8 \\
\hline Pequenas Centrais Hidrelétricas- & 71,3 \\
\hline Termelétrica Biomassa & 80,8 \\
\hline Usina Eólica & 100,9 \\
\hline Usina Solar Foto-Voltaica & 237,5 \\
\hline
\end{tabular}

Fonte: Brasil, Res. 233/99. Org. Sieben.

Conforme a tabela 1 as fontes alternativas de energia não são plausíveis, mas há de se considerar o próprio avanço na tecnologia nas opções e a questão de mercados que acabam interferindo nos valores normativos estabelecidos, podendo diminuir os custos das fontes mais caras. Muito provavelmente estes custos desconsiderem os transtornos causados aos atingidos pelas hidrelétricas.

A bioeletricidade do setor sucroenergético pretende fornecer $15 \%$ de energia utilizada no Brasil até o ano de 2020. Isto corresponde à geração de três usinas hidrelétricas de Belo Monte que a partir de 2019 pretende gerar em torno de 4 mil Mw. A matriz bioenergética promete $13.158 \mathrm{Mw}$ em 2020 . No ano de 2010 a bioenergia correspondeu a $5,4 \% \operatorname{com} 6.657 \mathrm{Mw}$, sendo comercializada em torno de R\$102/Mwh nas licitações em pregão (RIBEIRO, 2011).

Os estados de Mato Grosso do Sul, Minas Gerais e São Paulo concentram o maior número de usinas de comercialização de bioenergia do país, contudo há demais unidades em outros estados das regiões Sudeste, Centro-Oeste e Nordeste. Na região Norte, por exemplo, a usina de Pedro Afonso, localizada a $300 \mathrm{~km}$ de Palmas, no estado do Tocantins, receberá investimento de $\mathrm{R} \$ 32$ milhões para gerar $180 \mathrm{mil} \mathrm{Mwh}$ de energia a partir do ano de 2013 (RIBEIRO, 2011).

Os problemas ambientais e sociais ocasionados pela construção da Usina Hidrelétrica de Belo Monte e o retorno de um possível apagão ocasionado pelo crescimento econômico no país servem de justificativas do setor sucroenergético para entrar neste mercado. Apesar do discurso de energia limpa e em nível sustentável há de se observar aprofundadamente esta fonte energética como, por exemplo, o problema da concentração fundiária. $\mathrm{O}$ discurso de energia limpa também é questionável, e uma das poucas energias limpas é a solar, mesmo assim, o descarte do material das placas fotovoltaicas bem com o seu preço ainda se torna empecilho.

No Brasil se paga uma das tarifas mais caras do mundo. O custo de energia no país deveria ser de $\mathrm{R} \$ 25 / \mathrm{Mwh}$ e o preço médio atual gira em torno de $\mathrm{R} \$ 92 / \mathrm{Mwh}$. Isto se deve pelos altos tributos em nível federal e estadual que recaem sobre a energia no país. Tributos como o Programa de Integração Social (PIS), Contribuição para o Financiamento da Seguridade Social (Cofins) e Imposto sobre Circulação de Mercadorias e Serviços (ICMS) variam entre 25\% e $35 \%$ conforme o estado. No estado do Tocantins, que possui uma das mais altas tarifas do país estes tributos são aproximadamente de $30 \%$. Juntos os tributos e os encargos respondem entre $45 \%$ e $50 \%$ de tarifas de energia, colocando a energia do país entre as dez mais caras do mundo (RIBEIRO, 2011).

No Japão, por exemplo, que produz energia mais cara, mas com menos impostos, o consumidor paga menos, pois impostos e encargos giram em torno de $8 \%$. A alta tarifa elétrica também inibe investidores e empresas que procuram países com menores tarifas a fim de expandir plantas industriais. Um exemplo é a empresa Rio Tinto Alcan, produtora de alumínio que se instalou no Paraguai por causa da energia mais barata (GRANDIN; POLITO, 2011). De certa forma foi bom que a empresa procurasse outros locais para exercer seu domínio e sua exploração sobre os recursos e ainda fossem beneficiados com fornecimento de

Soc. \& Nat., Uberlândia, ano 24 n. 2, 183-196, mai/ago. 2012 
energia subsidiada. Contudo, evidencia-se que a energia elétrica produzida no Brasil é cara, não somente às empresa quanto sobretudo, onerosa à população.

Ressalta-se que a matriz energética paraguaia é a mesma do Brasil, com a Usina Hidrelétrica de Itaipu responsável pelo fornecimento de energia para aquele país. Apesar dos custos na geração de energia baixarem e o aumento da produção, sobretudo, de hidrelétricas, isto não significa tarifas mais baratas ao consumidor. Acrescenta-se que o lucro das empresas fornecedoras de energia ao longo do complexo energético (incluindo a fase de construção das obras) é enorme, aumentando os custos ao consumidor final.

A energia eólica pretende alcançar o patamar de produção de 7Gw em 2014, correspondendo a 5,4\% da matriz elétrica. Tal incremento se deve ao fato de as eólicas leiloarem energia a média de R \$99,56/Mwh, ficando com preços mais baixos que a geração hidrelétrica, perdendo somente para as usinas de Belo Monte e Teles Pires. A UHE de Belo Monte tem destaque pelos danos ambientais e sociais. A energia eólica pode concorrer com as hidrelétricas frente à dificuldade de obtenção de licenças ambientais das últimas. Até o ano de 2020 esta fonte alternativa poderá gerar $11.532 \mathrm{Mw}$ (GRANDIN; POLITO, 2011).

O coco babaçu (Orbignya martiana) poderia ser uma alternativa energética, pois já se tem tecnologia e, de forma insipiente, incentivos para a sua produção em biocombustíveis. A sua utilização em eletricidade possibilitaria manter camponeses e povos tradicionais nas áreas rurais, exercendo suas atividades. O estado do Tocantins tem ampla disponibilidade deste recurso em seu território, bem como camponeses tradicionais trabalhando com a palmeira.

A energia da UHE Estreito foi vendida por R\$ 126/Mwh, muito além da situação exposta pela ANEEL discutida na tabela 1 e muito mais cara que a energia eólica e a bioenergia. Desta forma, considerando os custos significativos, os impactos e efeitos ambientais, os problemas socioeconômicos, a desterritorialização camponesa, de povos tradicionais e de populações urbanas e a inundação de terras férteis tornam as matrizes hidrelétricas inviáveis e a necessidade por parte do governo brasileiro de rever a parte da Resolução 233/99 que estabelece os valores normativos de fornecimento de energia.
Assim sendo, contrariando a tabela 1, demonstra-se que as fontes alternativas em termos econômicos e sociais são menos onerosas. Há a necessidade de investir em projetos e estudos sobre as diversas fontes alternativas de energia no Brasil. É necessário rever a política energética que na atual conjuntura beneficia setores ligados à construção de hidrelétricas.

\section{AAMAZÔNIAEAMONOCULTURADAS ÁGUAS}

Segundo a Comissão Mundial de Barragens (2000) no mundo já foram construídas mais de 800 mil barragens, sendo 45 mil de grande porte. Tais empreendimentos deslocam cerca de 4 milhões de pessoas por ano. O Brasil é um dos vinte países onde esta matriz representa a principal fonte de energia, deslocando mais de 1 milhão de pessoas nas suas 2 mil barragens construídas (NOGUEIRA, 2007).

Experiências anteriores mostraram que a implantação de uma usina hidrelétrica sempre ocasionou grandes transformações para o ambiente e as populações atingidas. As empresas, grupos ou consórcios muitas vezes ou jamais se preocupam com os impactos negativos que tais empreendimentos acarretarão.

Conforme Becker (1982, p. 225): "Deslocam-se pequenos proprietários de áreas a serem invadidas por águas de represa, como em Tucuruí, pagando indenização ou oferecendo-lhes em troca terras menos acessíveis e menos valiosas..." Tucuruí foi a primeira grande hidrelétrica da região norte e que causou inúmeros problemas sociais à população carente atingida. Tal represa teve grandes investimentos estatais na década de 1970.

A política energética está se expandindo com mais intensidade para os rios da região norte do país. Esta matriz energética já desterritorializou os sujeitos e represou os rios de planalto nas regiões Sul e Sudeste. A população das regiões Sudeste e Sul está mais esclarecida com os efeitos das hidrelétricas e a valorização da terra das regiões meridionais aumentou os custos com as indenizações. Os rios da região Norte são o novo alvo constituindo uma verdadeira monocultura das águas como afirma Pinto (2002).

Essa nova realidade estaria coerente com o fato de a Amazônia dispor de $20 \%$ do sistema 
hidrográfico do planeta, um caudal de águas que poderia proporcionar a geração de $50 \mathrm{mil}$ megawats de energia, apenas $15 \%$ menos do que a produção total do Brasil no momento. No espaço de apenas três décadas, o ingresso da Amazônia no mercado energético nacional quase provocaria a duplicação da geração. (PINTO, 2002, p. 46).

A cobiçada região Amazônica tem uma grande função dentro dos grandiosos e mega projetos por deter $1 / 5$ das reservas mundiais de água doce em rios. "Esse desempenho realmente impressionante talvez esteja ofuscando a percepção de um fato: a especialização dos rios amazônicos na monocultura energética" (PINTO, 2002, p. 47). A monocultura das águas para a produção de energia elétrica é como todas as outras monoculturas brasileiras, é mais uma que atende aos interesses capitalistas.

Mas já era pra ser diferente. A recente legislação sobre recursos hídricos exige uma visão de conjunto das bacias, multifacetada e com capacidade de antecipação dos fatos. Como de regra, porém, a boa lei parece letra morta. Quem toma as decisões sobre o aproveitamento das águas é quem constrói grandes barragens para uso energético. Não há, acima de sua cabeça, nenhuma agência de desenvolvimento para impor-lhes controle e regulamentos, impedindo a monocultura dos megawatts. (PINTO, 2002, p. 49).

"No Brasil, cerca de $20 \%$ da energia produzida é agregada a produtos destinados à exportação, em particular, o alumínio" (ZITZKE, 2007, p. 95). O complexo hidrelétrico do rio Tocantins atende principalmente às necessidades de energia das empresas japonesas de produção de Alumínio. A multinacional japonesa instalou-se no norte do país a partir da década de 1970 a fim de transformar a bauxita extraída no estado do Pará em alumínio, necessário as suas indústrias eletro intensivas localizadas no outro lado do planeta. A empresa japonesa é uma das principais usuárias da energia produzida pela Usina Hidrelétrica de Tucuruí (PINTO, 2002).
O imenso potencial energético do Brasil está sendo usado para produzir alumínio, subsidiado escandalosamente, tirando o pão da boca do necessitado para enriquecer empresas internacionais de alumínio. 600 milhões de reais em subsidios; já foi muito mais, pois já foram bilhões de dólares no passado. Como é que se explica uma coisa dessas? Como é que se justifica? Para que ter governo se não se tem coragem de colocar essa gente na cadeia? (VIDAL, 2007, p. 101).

Pinto (2002) manifestou que o objetivo da empresa japonesa era produzir matéria-prima para as suas indústrias a baixos custos energéticos. Esta medida vem sendo tomada desde as ameaças do aumento do petróleo na década de 1970. A indústria japonesa estava-se precavendo da crise do petróleo, buscando em terras tupiniquins a matéria-prima e a sua parcial industrialização a baixos custos energéticos para, assim ser embarcado pelo porto de Itaqui até o Japão onde recebe um tratamento refinado e agrega-se exuberantes valores ao material industrializado e comercializado.

O complexo do alumínio tem seu ciclo completo com o represamento do rio Tocantins. Primeiramente com a hidrelétrica de Tucuruí, após outras hidrelétricas instaladas ao longo de seu trecho e atualmente a UHE de Estreito. Foi a companhia japonesa, inclusive a responsável pela hidreletricidade nas baixas latitudes geográficas do Brasil, pois antes disto o governo brasileiro não tinha interesse na geração de energia nesta região.

Mas o Japão não dispunha de fontes de energia. Nem adequadas e muito menos abundantes e baratas. Iria ter que fechar todas as suas fábricas de alumínio, como acabou fazendo, e abrir novas plantas industriais fora de seu território. Algumas ficaram nos satélites asiáticos. Mas a maior seria montada a 20 mil quilômetros de distância, na Amazônia. Essa fábrica, sozinha, deveria responder por metade das necessidades da indústria japonesa, produzindo 600 mil toneladas por ano. Equivalia a cinco vezes a produção brasileira de alumínio de então. (PINTO, 2002, p. 121).

Soc. \& Nat., Uberlândia, ano 24 n. 2, 183-196, mai/ago. 2012 
Os impactos sociais e ambientais tinham como discurso e justificativa o benefício elétrico para a população local e regional. Dos $3500 \mathrm{Mw}$ produzidos por Tucuruí $1 / 3$ são destinados para a indústria de alumínio. Da energia hidrelétrica produzida por Estreito grande parte irá para a indústria de alumínio instalada nos estados do Maranhão e do Pará. De Tucuruí, outro $1 / 3$ é exportado e o restante fica para o próprio estado do Pará, para as demais necessidades energéticas. Resumindo, para a região ficam os rejeitos, enquanto os proveitos direcionam-se para outras localidades.

\section{A MONOCULTURA DAS ÁGUAS NO ESTADO DO TOCANTINS}

O aumento da produção hidrelétrica pauta-se na necessidade de atender aos atuais eixos econômicos e formar novos grandes complexos econômicos. O estado do Tocantins ganha destaque pela sua emancipação política, objetivando ser um exemplo de modernidade e crescimento no Brasil, pautado no discurso do desenvolvimento sustentável. Nesta perspectiva de modernidade as famílias camponesas tradicionais de beira de rio, onde os ciclos da natureza ditam tempo e espaço, não têm lugar.

A construção da UHE de Lajeado teve apoio irrestrito do governo do estado do Tocantins. A hidrelétrica não considerou a produção de auto-consumo das famílias (ZITZKE, 2007). No caso da UHE Estreito ocorreu o apoio dos governos estaduais do Maranhão e do Tocantins, desconsiderando a produção das populações atingidas que abasteciam mercados locais com as suas mercadorias.

No mapa 2 nota-se o potencial hidrelétrico do estado do Tocantins. É perceptível a grande concentração de hidroelétricas na bacia hidrográfica do rio Tocantins. Isto se deve, sobretudo, às condições naturais de se constituir em rio mais encaixado e em alguns locais com a presença de corredeiras. Percebe-se que o rio Tocantins terá uma sucessão de lagos artificiais.

As UHE's de Estreito e de Lajeado, as principais, já estão em funcionamento, localizadas respectivamente nos municípios de Aguiarnópolis na divisa com o estado Maranhão na porção norte do estado e a segunda próxima a capital, Palmas na parte central do estado (Mapa 2). A UHE Lajeado foi concluída no início do novo milênio e a UHE Estreito terminada no final do ano de 2010.

No rio Tocantins, no estado homônimo, ainda estão previstas de montante a jusante as: UHE de Peixe (em fase de implantação) e UHE de Ipueiras (em fase de viabilização) ambas localizadas na porção sul, a UHE de Tupiratins (viabilidade) na parte central, e a UHE Serra Quebrada (em fase de projeto) na porção norte do estado fazendo divisa com o estado do Maranhão. A sequência de montante a jusante será: Peixe, Ipueiras, Lajeado, Tupiratins, Estreito e Serra Quebrada (Figura 02).

O mapa 2 mostra várias outras hidroelétricas menores planejadas ou já existentes, sobretudo em canais afluentes do rio Tocantins, localizados a sudoeste do estado. No rio Araguaia, o destaque é para a futura UHE de Santa Isabel localizada na divisa com o estado do Pará na porção norte. Ressalta ainda que o complexo de lagos no rio Tocantins servirão de várias maneiras, sobretudo como hidrovia e ainda como regulador de vazão a fim de utilizar a capacidade máxima na expansão da construção da $2^{\circ}$ fase da UHE de Tucuruí.

Até o ano de 2008, estavam em operação 14 UHE's no estado contabilizando uma potência de $1.403 \mathrm{Mw}$, atingindo uma área de aproximadamente $940 \mathrm{Km}^{2}$. As usinas projetadas eram 13 e gerariam $6.422 \mathrm{Mw}$ atingindo área em torno de $4 \mathrm{mil} \mathrm{Km}^{2}$. As usinas em construção contabilizaram 8 e gerariam em torno de $1.212 \mathrm{Mw}$, atingindo área estimada de $690 \mathrm{Km}^{2}$ (Mapa 2). Acrescenta que a UHE Estreito encontrava-se nesta situação no ano de 2008.

Com o governo popular e o crescimento econômico que demanda maior necessidade energética e o interesse de complexo de empreiteiras a solução proposta e aceita foi a construção de barragens nos rios já barrados e, principalmente, nos canais fluviais da Amazônia, onde uma população menor e menos informada traria menos problemas de opinião pública.

Assim foram construídas as hidrelétricas do rio Tocantins, inclusive a UHE Estreito, causando uma série de transtornos sociais e mudanças ambientais, porém sustentando a ideia de conciliação de interesses econômicos, ecológicos e sociais, pautado no desenvolvimento sustentável. 
Figura 02 - Potencial hidrelétrico do estado do Tocantins

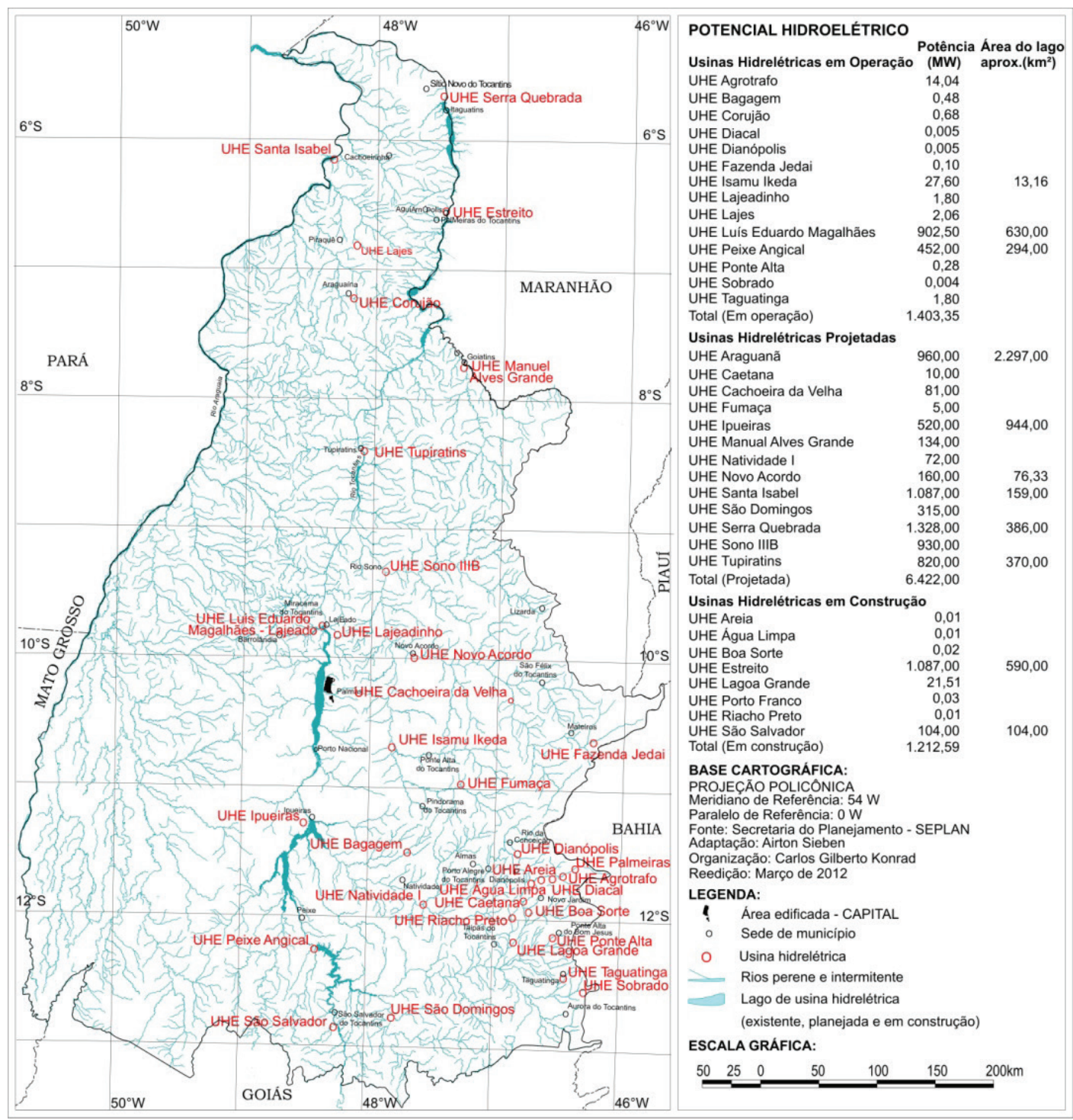

Fonte: SEPLAN, 2008 Adaptado por Sieben, A. e Konrad, C. G. 03/2012

\section{AS MANIFESTAÇÕES DOS CAMPONESES TRADICIONAIS DE PALMATUBA}

Percebendo a deterioração dos seus modos de vida foi necessário às categorias de camponeses e de povos tradicionais reivindicar o que lhes é devido. A fim de ganhar legitimidade política, muitas categorias minoritárias se organizaram em associações e movimentos para lutarem por seus direitos e ganharem visibilidade dentro do contexto nacional e internacional.

Nos reassentamento os atingidos têm maior poder de mobilização. No caso de Palmatuba isto não ocorreu devido ao distanciamento das famílias que por não serem reassentadas espalharam-se dificultando a comunicação. As distâncias foram um condicionante importante que dificultou a articulação em reivindicações e manifestações.

No Brasil há uma legislação ambiental avançada de nível superior a de países ricos, contudo os movimentos ambientalistas não obtiveram êxito no combate às desigualdades sociais e degradação ambiental (ZITZKE, 2007). Observa-se que os governos

Soc. \& Nat., Uberlândia, ano 24 n. 2, 183-196, mai/ago. 2012 
de "esquerda" no Brasil do início do novo milênio não sinalizaram radicais mudanças neste contexto.

Germani (2003) classificou como débeis as manifestações de prefeitos a fim de pedir somente alguma compensação pelo prejuízo, ao invés de questionar a hidrelétrica de Itaipu. Todo estado do Paraná perdeu em terras férteis e riquezas naturais, sem a sua devida consulta. Acrescenta-se que no caso da UHE de Estreito tal situação se repetiu.

\section{A drástica redução da autonomia dos estados e municípios nos últimos anos resultou de uma politica centralizadora, onde o poder Federalé quem determina a execução de grandes projetos que interessam ao processo de acumulação de capital e cabe aos poderes estadual e municipal aceitar as determinações superiores, legitimá- -las de alguma forma e "encaixá-las" em seus planos (GERMANI, 2003, p. 42).}

As medidas e decisões tomadas desta maneira conforme ressaltado por Germani (2003) acabam irremediavelmente causando conflitos ou no mínimo levam a situações de contestação por parte de uma camada da sociedade descontente. E esta sociedade na luta por seus direito se organiza a fim de receberem o mínimo possível por todo transtorno causado às suas vidas.

No caso da UHE Estreito e no lugar de estudo, o Movimento de Atingidos por Barragens (MAB) foi desacreditado por algumas pessoas segundo informações dos atingidos e assim este não conseguiu penetração no povoado de Palmatuba e dar orientação no processo de indenização. O movimento era desconhecido por grande parte de camponeses, povos tradicionais e população urbana atingida, gerando desconfianças promovidas por algumas pessoas, sobretudo, ligadas a política que até então eram tidas de confiança pela comunidade.

$\mathrm{O}$ MAB, primeiramente, foi visto com desconfiança pelos atingidos da UHE de Lajeado. Isto deve-se pelo desconhecimento local sobre este movimento. As primeiras atuações foram no sentido de elaborar reuniões e estratégias como levar líderes locais para reassentamentos no sul do país, atingidos por barragens a fim de propiciar ideias e exemplos aplicados no caso tocantinense (ZITZKE, 2007). "O MAB iniciou, então, o debate sobre a construção de uma organização regional sem se preocupar com as associações existentes na região, que tinham como principais objetivos as questões ligadas a políticos locais" (ZITZKE, 2007, p. 176).

Em 2010 foram registrados diversos atos em favor da Reforma Agrária e outros protestos contra a violência, ou pedindo a desapropriação, ou regularização de terras, renegociação de dividas, incentivo à pequena produção, em defesa da soberania alimentar, contra a privatização da água e a construção de barragens e em defesa do meio ambiente. Estes atos culminaram em ocupações de prédios públicos, acampamentos, caminhadas, passeatas e bloqueios de ferrovia, balsa e rodovias. Também foram registrados diversos atos pelo país contra a impunidade, a injustiça e a violência no campo. (CLEPS JUNIOR, 2011, p. 139).

A UHE Lajeado promoveu conflitos socioambientais, ocasionando as manifestações de ocupação e acampamento no escritório do empreendedor, por parte dos atingidos. Tais manifestações foram decorrentes do tratamento indiferente dado aos atingidos pelos técnicos do empreendimento e do governo, bem como serem reconhecidos em suas reivindicações. O MAB representou uma ameaça ao Consórcio INVESTCO, diante de sua influência nos atingidos e poder de mobilização e organização para as reivindicações (ZITZKE, 2007).

Cleps Junior (2011) manifestou que os conflitos pela água aumentaram no contexto da Amazônia. A construção da Usina Hidrelétrica de Belo Monte ganhou destaque na discussão das águas e da construção de barragens, atingindo ribeirinhos. O estado do Tocantins também teve manifestações inerentes ao conflito da água na construção de hidrelétricas.

No caso de Estreito o MAB, o Movimento Sem Terra (MST) com o apoio da Comissão Pastoral da Terra (CPT) tiveram ação efetiva por ocasião das manifestações em frente ao pátio de entrada da hidrelétrica. Vários outros momentos foram importantes a fim de organizar os movimentos de reivindicação dos direitos podados dos atingidos e sensibilizar a comunidade como um todo. 
Na Figura 03 observa-se a manifestação dos atingidos em Estreito, próximo à entrada da construção da UHE. A marcha dos manifestantes foi interrompida pela ação da polícia militar do estado do Maranhão em agosto de 2010. Na manifestação houve o trabalho da polícia Federal a fim de organizar o tráfego interrompido na $\mathrm{BR} 010$ próximo à cidade de Estreito e o batalhão de choque a fim de evitar a entrada os manifestantes no pátio de obras de construção da represa, localizada próximo da cidade.
Observa-se a presença dos manifestantes na fotografia 1. A polícia militar formada pelo batalhão de choque e cavalarianos à sua frente, impedindo a passagem dos manifestantes. O que se observou foi um embate entre duas classes desfavorecidas. De um lado pescadores camponeses, povos tradicionais, quebradeiras de coco, índios e do outro lado soldados. Muito provavelmente e considerando Germani (2003) os soldados sejam filhos ou parentes próximos dos manifestantes, da mesma forma como ocorreu nos conflitos de Itaipu.

Figura 03. Manifestação em Estreito (MA) na BR 010: entrada da construção UHEE

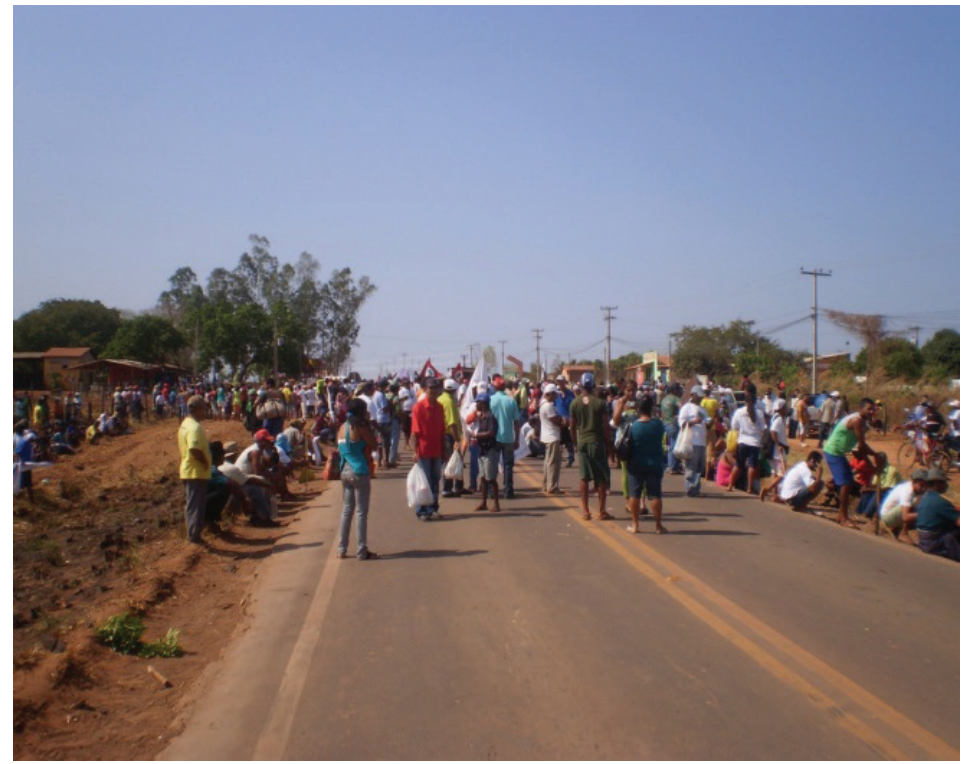

Foto: Sieben, 23/08/2010

No dia da manifestação (Figura 03) e no horário de meio dia o sol no local era escaldante e as duas categorias (policiais e manifestantes) enfrentaram-se por longas horas a espera neste ambiente até que se sinalizasse uma atitude por parte do CESTE em termos de conversação com os atingidos. É perceptível na paisagem a quase ausência de vegetação que pudesse servir de abrigo para ambas as categorias. No mês de agosto o clima na região é bastante quente e seco e a quase total ausência de nuvens por ocasião da dinâmica climática.

Os manifestantes, por sua vez, já estavam bastante cansados, mas não desanimados. Eles tinham feito caminhada de 10 dias pela BR 226 (trecho Belém-Brasília) de 130 quilômetros entre as cidades de Araguaína (TO) e Estreito (MA) e estavam a pou- cos metros da entrada da construção da barragem. A marcha iniciou no dia 13/08/2010 em Araguaína, na medida que avançavam mais atingidos e outras pessoas se juntaram na mobilização. A caminhada iniciou com aproximadamente 150 pessoas, culminando em torno de 1 mil no dia da manifestação em Estreito.

Os camponeses e soldados irremediavelmente são vítimas do enredo feito por capital (classe burguesa) e Estado. Sempre é possível extrair algo mais dos camponeses ou das classes desfavorecidas como um todo, inclusive o embate entre elas, sendo considerado um trunfo do Estado.

Projetos hidrelétricos como Itaipu, Sobradinho, Tucuruí, Lajeado, Estreito entre inúmeros outras tiveram orçamentos de bilhões de reais. Diante das dificuldades impostas nas indenizações surge a pergunta:

Soc. \& Nat., Uberlândia, ano 24 n. 2, 183-196, mai/ago. 2012 
porque o empreendedor dificulta tanto? Haja vista que as indenizações são irrisórias frente ao orçamento total dos projetos.

No caso da UHE Estreito ocorreram apropriações indevidas, há casos de indenizações duplamente pagas pelo CESTE e que não chegaram ao devido atingido. Provavelmente os desvios e as indenizações duplas serão pagos por toda a sociedade nas tarifas de contas de luz. Pois a forma de o Estado lucrar com a situação é nos impostos e encargos, encarecendo as tarifas energéticas, bem como a energia produzida pelo empreendedor deverá proporcionar lucro a este.

No mês de maio de 2010, alguns palmatubenses em visita ao escritório do empreendedor na cidade de Carolina (MA), reivindicaram melhor indenização por barracões onde quebravam coco babaçu. Notou-se a forma dissimulada e pouco respeitosa por parte de funcionários da empresa em atender às reivindicações dos atingidos. Na mesa de negociação, a estratégia dos funcionários da empresa foi de desconstruir as alegações dos atingidos. Depois de muitas evasivas sobre o assunto que realmente interessava, ficou resolvido que o funcionário responsável faria uma proposta ao CESTE para que este a analisasse.

Percebeu-se que as estratégias da empresa foram muitas para ludibriar a população atingida, inclusive manifestando que tal indenização já havia sido paga. Questionada sobre quem teria se apropriado desta indenização, os atingidos obtiveram somente respostas evasivas. Aproveitando-se da simplicidade destas pessoas ficou fácil manipular dados e informações. A reunião foi demorada e os camponeses tradicionais de Palmatuba não obtiveram nada em definitivo.

\section{CONSIDERAÇÕES FINAIS}

Analisando de forma geral a implantação de UHE de Estreito na perspectiva do Estado, percebe-se um rol de justificativas para a sua instalação. Por outro lado os aspectos negativos baseados nos impactos negativos aos atingidos e também ao ambiente não foram considerados.

As análises técnicas e de custo benefício foram unicamente avaliadas na hidrelétrica em questão como em todas as outras já instaladas e em processo de implantação. Há de se ter outras matrizes elétricas que baixem o custo ao consumidor final e que agridam menos comunidades tradicionais e camponesas desterritorializadas pelo processo.

Por fim e pensando em alternativas, resolvendo, mesmo que parcialmente, o problema energético e dos povos tradicionais e camponeses em questão poderiam ser implantadas políticas energéticas que visassem o uso alternativo do coco babaçu, abundante na região para a produção elétrica. Tecnologia, recurso natural (babaçu) e população para trabalhar com esta alternativa existem no Brasil e que poderiam ser utilizadas em grande parte da região Amazônica, diminuindo a construção de barragens e impactando menos sociedade e ambiente.

\section{REFERÊNCIAS}

BECKER, Bertha K. Geopolitica da Amazônia: a nova fronteira de recursos. Rio de Janeiro: Zahar Editores, 1982.

BRASIL. Decreto $n^{\circ} 24.643 / 34$, de 10, de julho de 1934. Disponível em <http://www.planalto. gov.br/ccivil_03/decreto/d24643.htm $>$, acesso em 26/11/2011.

BRASIL. Lei $n^{\circ}$ 6938/81, de 31, de agosto de 1981 . Disponível em $<$ http://www.planalto.gov.br/ccivil_03/ leis/L6938.htm>, acesso em 26/11/2011.

BRASIL. Lei $n^{\circ}$ 9.984/2000, de 17, de julho de 2000 . Disponível em $<$ http://www.planalto.gov.br/ccivil_03/ leis/L9984.htm>, acesso em 26/11/2011.

BRASIL. Medida Provisória $n^{\circ}$ 2.198-5/2001, de 24, de agosto de 2001. Disponível em <http://www. planalto.gov.br/ccivil_03/mpv/Antigas_2001/2198-5. htm>, acesso em 26/11/2011.

BRASIL. Resolução $n^{\circ}$ 06/87, de 16 de setembro de 1987. Disponível em <http://www.mma.gov.br/ port/conama/res/res87/res0687.html>, acesso em 26/11/2011. 
Política energética na Amazônia: a UHE Estreito e os camponeses tradicionais de Palmatuba/Babaçulândia (TO)

Airton Sieben , João Cleps Junior

BRASIL. Resolução $n^{\circ}$ 233/99, de 29 de julho de 1999. Disponível em <http://www.aneel.gov.br/cedoc/ RES1999233.pdf>, acesso em 03/08/2011.

CAPPIO, Luiz F. Água é dom de Deus: cuidado, solidariedade e co-responsabilidade. Fórum Nacional da Terra e da Água: reforma agrária, democracia e desenvolvimento sustentável. Coordenação de Sérgio Bauer; transcrição das palavras Bruno Borges. 1. ed. São Paulo: Expressão Popular, 2007.

CLEPS JUNIOR, João. As ações dos movimentos sociais no campo em 2010: ocupações, acampamentos e manifestações. In: . Conflitos no Campo Brasil 2010/CPT. Goiânia: CPT, 2011. 184 p. p. 136-143.

CNEC. Estudos de Viabilidade da UHE Estreito: Relatório de Impacto Ambiental - RIMA 2001.

COMISSÃO MUNDIAL DE BARRAGENS. Novembro de 2000. Disponível em <http://hqweb.unep.org/ dams/WCD/report/WCD\%20report_Barrages $\% 20$ et $\% 20 \mathrm{D} \% \mathrm{C} 3 \% \mathrm{~A} 9 \mathrm{veloppement}$.pr\%C3\%A9face. pdf>, acesso em 26/11/2011.

GERMANI, Guiomar I. Expropriados Terra éágua: o conflito de Itaipu. Salvador: EDUFBA/ULBRA, 2003.

GRANDIN, Felipe e POLITO, Rodrigo. Eólicas surpreendem com preços mais baixos que hidrelétricas. Brasil Energia. Rio de Janeiro, n. 370. ano 30, p. 86 -94, set. 2011.

IBGE. Instituto Brasileiro de Geografia e Estatística. Disponível em <ftp://geoftp.ibge.gov.br/mapas/tematicos/mapas_murais/logistica/energia/2006.pdf $>$, acesso em 31/10/2011.

IBGE. Instituto Brasileiro de Geografia e Estatística. Disponível em < ftp:/geoftp.ibge.gov.br/mapas_tematicos/mapas_murais/brasil_2004.pdf $>$, acesso em $21 / 01 / 2012$

NOGUEIRA, Narayana de D. A usina Hidrelétrica Cachoeira do Emboque - MG: o significado da bar- ragem para os atingidos. Dissertação (Mestrado em Extensão Rural) UFV/Viçosa, 2007.

PINTO, Lúcio F. Hidrelétricas na Amazônia: predestinação, fatalidade ou engodo? Belém: Edição Jornal Pessoa, 2002.

RIBEIRO, Juliana. Setor sucroenergético volta os olhos para a produção de bioeletricidade e se prepara para conquistar $15 \%$ do fornecimento de energia brasileira até 2020. Dinheiro Rural. São Paulo, n.83, p. 63-67, set. 2011.

ROUSSEFF, Dilma V. As ações governamentais na área de energia elétrica. Fórum Nacional da Terra e da Água: reforma agrária, democracia e desenvolvimento sustentável. Coordenação de Sérgio Bauer; transcrição das palavras Bruno Borges. São Paulo: Expressão Popular, 2007.

SEPLAN. Atlas do Tocantins: subsídios ao planejamento da gestão territorial. Diretoria de Zoneamento Ecológico-Econômico - DZE. 5. ed. Palmas: Secretaria do Planejamento e Meio Ambiente, 2008. 62 p.

SIGAUD, Lygia. O efeito das tecnologias sobre as comunidades rurais: o caso das grandes barragens. 18 (7), fev. 1992. Disponível em: <http://www.anpocs. org.br/portal/publicacoes/rbcs_00_18/rbcs18_02. htm>, acesso em: 31/03/2012.

VIDAL, Baustista. O imperativo de fontes alternativas de energia. Fórum Nacional da Terra e da Água: reforma agrária, democracia e desenvolvimento sustentável. Coordenação de Sérgio Bauer; transcrição das palavras Bruno Borges. São Paulo: Expressão Popular, 2007.

ZITZKE, Valdir A. A rede sociotecnica da Usina Hidrelétrica do Lajeado (TO) e os reassentamentos rurais das famílias atingidas. 2007. 316 f. Tese (Doutorado em Ciências Humanas, Sociedade e Meio ambiente) Centro de Filosofia e Ciências Humanas, UFSC/ Florianópolis, 2007.

Soc. \& Nat., Uberlândia, ano 24 n. 2, 183-196, mai/ago. 2012 